\title{
Staphylococcus aureus contamination of environmental surfaces and efficacy of alcohol wiping once daily in a hospital with a long-term care facility
}

\author{
Kumiko Maeda ${ }^{* 1}$, Shigeharu Oie ${ }^{2}$, Hiroyuki Furukawa ${ }^{2}$ \\ ${ }^{1}$ Department of Pharmacy, Mine City Hospital, Higashibun, Omine-cho, Mine, Japan \\ ${ }^{2}$ Department of Pharmacy, Yamaguchi University Hospital, Minamikogushi, Ube, Japan
}

Received: June 5, 2015

DOI: $10.5430 /$ jha.v4n6p31
Accepted: July 31, 2015

Online Published: August 11, 2015

\begin{abstract}
We evaluated Staphylococcus aureus contamination of door and wheelchair handles in a hospital with a care facility. In the hospital, 11 (27.5\%) of 40 door handle sites and 7 (28.0\%) of 25 wheelchair handle sites were contaminated. The $S$. aureus contamination density (mean $\pm S D$ ) was $9.8 \pm 14.0$ colony-forming units (cfu) for door handles and $285.0 \pm 731.6 \mathrm{cfu}$ for wheelchair handles. In the long-term care facility, 18 (51.4\%) of 35 door handle sites and $9(36.0 \%)$ of 25 wheelchair handle sites were contaminated. The $S$. aureus contamination density was $215.3 \pm 657.5 \mathrm{cfu}$ for door handles and $295.7 \pm 702.0 \mathrm{cfu}$ for wheelchair handles. Because $S$. aureus contamination was frequently observed not only in the hospital but also in the care facility, we performed an evaluation to determine whether disinfection by wiping with alcohol once daily was effective for maintaining the cleanliness of door handles. S. aureus contamination was compared between door handles 24 hours after disinfection by wiping with $80 \%$ (v/v) ethanol once daily for 5 consecutive days (disinfection group) and door handles not disinfected for 5 days following a single disinfection with $80 \%(\mathrm{v} / \mathrm{v})$ ethanol (nondisinfection group). The $S$. aureus level did not differ significantly between the disinfection and nondisinfection groups. Disinfection by wiping with alcohol at 24-hour intervals was not always effective in maintaining the cleanliness of door handles.
\end{abstract}

Key Words: Staphylococcus aureus, Methicillin-resistant Staphylococcus aureus, Door handle, Wheelchair, Contamination, Disinfection

\section{INTRODUCTION}

Environmental contamination has been linked to methicillinresistant Staphylococcus aureus (MRSA) transmission in hospitals. ${ }^{[1-6]}$ In addition, a previous study showed a decrease in the MRSA detection rate after the improvement of environmental cleaning/disinfection methods. ${ }^{\text {[] }}$ Therefore, in terms of MRSA infection, the disinfection of environmental surfaces such as door handles is important. ${ }^{[8-10]}$ However, the appropriate frequency of disinfecting frequently touched surfaces has not be adequately evaluated, although there is a prevailing opinion that MRSA patient rooms should be disinfected 3 times daily in intensive care units and once daily on normal wards. ${ }^{[11]}$ Therefore, in a hospital with a care facility, we quantitatively evaluated methicillin-sensitive S. aureus (MSSA) and/or MRSA contamination of door and wheelchair handles and determined whether the disinfection

\footnotetext{
*Correspondence: Kumiko Maeda; Email: maeda-935@umin.ac.jp; Address: Department of Pharmacy, Mine City Hospital, 1313-1 Higashibun, Omine-cho, Mine 759-2212, Japan.
} 
of door handles by wiping with alcohol once daily is effective in maintaining cleanliness.

\section{MATERIALS AND METHODS}

Between October 2010 and March 2011, we investigated $S$. aureus contamination of door and wheelchair handles using the gauze wiping method in Mine City Hospital (145 beds) and its affiliated long-term care health facility (70 beds). A total of 40 of door handle sites and 25 wheelchair handle sites in the hospital and 35 door handle sites and 25 wheelchair handle sites in the care facility were investigated. The twin handles on a door inside and outside a room were considered as a single site. For wheelchairs, the left and right handles were investigated as a single site. In the institutions investigated in this study, no regular disinfection and cleaning of door handles or wheelchairs was performed.

Subsequently, we determined whether wiping with sterile gauze $(25 \mathrm{~cm} \times 25 \mathrm{~cm}, 100 \%$ polyester $)$ soaked in $80 \%(\mathrm{v} / \mathrm{v})$ ethanol (Kenei Pharmaceutical Co., Ltd., Osaka, Japan) at 24-h intervals was effective in preventing $S$. aureus contamination of door handles. A total of 75 door handle sites was investigated. Door handles wiped with alcohol at 24-h intervals for 5 consecutive days (disinfection group) were compared with those not disinfected for 5 consecutive days after a single disinfection with alcohol (nondisinfection group). The handles were randomly assigned to the disinfection or nondisinfection group. No S. aureus was detected on 35 door handle sites immediately after wiping with sterile gauze soaked in $80 \%$ (v/v) ethanol.

\subsection{Quantification of MRSA and MSSA on surfaces wiped with gauze}

The surface of each door and wheelchair handle was wiped using sterile gauze $(6 \mathrm{~cm} \times 5 \mathrm{~cm} ; 100 \%$ cotton $)$ moistened with sterile physiological saline. The gauze used for wiping was then placed in a tube containing $3 \mathrm{ml}$ of sterile broth. The tube was manually stirred for about $5 \mathrm{~s}$ and ultrasonicated (Sine Sonic 100, Ikemoto Rikagaku Co., Tokyo, Japan) at $36 \mathrm{kHz}$ for $10 \mathrm{~min} .{ }^{[12]}$ Two aliquots $(0.5 \mathrm{ml}$ each $)$ of an undiluted sample were plated on one salt egg yolk agar plate (Nissui Pharmaceutical, Co., Tokyo, Japan). These plates were incubated for $48 \mathrm{~h}$ at $35^{\circ} \mathrm{C}$, and colony-forming units (cfu) were then counted. Yellow colonies on the plates with a pearl-ring formation in the surrounding medium were subjected to Gram staining, morphological examination, the coagulase test (Staphylo La Seiken, Denka Seiken Co., Tokyo, Japan), and testing with an Api Staph (Analytab Products, Plain View, NY, USA) to determine whether they were $S$. aureus.

The methicillin sensitivity of cultured $S$. aureus was determined using an MRSA screening agar containing $6 \mu \mathrm{g} / \mathrm{ml}$ of oxacillin (Nippon Becton Dickinson Co., Tokyo, Japan). When 30 or more cfu of $S$. aureus were detected, 8 colonies were randomly selected and their methicillin sensitivity was determined. The MRSA or MSSA count per door and wheelchair handle was estimated from the ratio of methicillinresistant to methicillin-sensitive colonies.

\subsection{Statistical analysis}

Differences between groups were analyzed using the Wilcoxon signed-rank test.

\section{RESULTS}

Table 1 shows $S$. aureus contamination of door handles in the hospital and affiliated long-term care facility. In the hospital, the $S$. aureus (MSSA and/or MRSA) contamination rate was $27.5 \%$, and the MRSA contamination rate was $17.5 \%$. In the care facility, the $S$. aureus contamination rate was $51.4 \%$, and the MRSA contamination rate was 5.7\%. The MSSA contamination density per door handle was 3-2,850 cfu, and the MRSA contamination density per door handle was 3-39 cfu.

Table 1. Contamination of door handles by MSSA/MRSA in a hospital with a long-term care facility

\begin{tabular}{|c|c|c|c|c|c|c|}
\hline \multirow{2}{*}{ Site } & \multirow{2}{*}{ Contaminant } & \multirow{2}{*}{$\begin{array}{l}\text { No. of door handles } \\
\text { contaminated/No. examined (\%) }\end{array}$} & \multicolumn{4}{|c|}{ Door handle contamination density (cfu/door handle) } \\
\hline & & & 3-9 & 10-99 & 100-999 & $1,000-9,999$ \\
\hline \multirow{4}{*}{ Hospital } & MSSA & $1 / 40(2.5)$ & 1 & 0 & 0 & 0 \\
\hline & MRSA & $7 / 40(17.5)$ & 6 & 1 & 0 & 0 \\
\hline & MSSA and MRSA & $3 / 40(7.5)$ & 2 & 1 & 0 & 0 \\
\hline & MSSA and/or MRSA & $11 / 40(27.5)$ & 9 & 2 & 0 & 0 \\
\hline \multirow{4}{*}{$\begin{array}{l}\text { Long-term } \\
\text { care facility }\end{array}$} & MSSA & $14 / 35(40.0)$ & 8 & 4 & 1 & 1 \\
\hline & MRSA & 2/35 (5.7) & 0 & 2 & 0 & 0 \\
\hline & MSSA and MRSA & $1 / 35$ (2.9) & 0 & 0 & 1 & 0 \\
\hline & MSSA and/or MRSA & $18 / 35(51.4)$ & 8 & 7 & 2 & 1 \\
\hline
\end{tabular}

Note. The door handles inside and outside a room were considered as a single site 
Table 2 shows S. aureus contamination of wheelchair handles cility, the respective rates were $36.0 \%$ and $0 \%$. The MSSA in the hospital and affiliated long-term care health facility. contamination density per wheelchair handle was 3-2,160 In the hospital, the $S$. aureus contamination rate was $28.0 \%$, cfu, and that of MRSA was 3-6 cfu. and the MRSA contamination rate was $4 \%$. In the care fa-

Table 2. Contamination of wheelchair handles by MSSA/MRSA in a hospital with a long-term care facility

\begin{tabular}{|c|c|c|c|c|c|c|}
\hline \multirow{2}{*}{ Site } & \multirow{2}{*}{ Contaminant } & \multirow{2}{*}{$\begin{array}{l}\text { No. of wheelchair handles } \\
\text { contaminated/No. examined (\%) }\end{array}$} & \multicolumn{4}{|c|}{ Wheelchair handle contamination density (cfu/wheelchair handle) } \\
\hline & & & $3-9$ & $10-99$ & $100-999$ & $1,000-9,999$ \\
\hline \multirow{4}{*}{ Hospital } & MSSA & $5 / 25(20.0)$ & 3 & 1 & 0 & 1 \\
\hline & MRSA & $1 / 25(4.0)$ & 1 & 0 & 0 & 0 \\
\hline & MSSA and MRSA & $1 / 25(4.0)$ & 1 & 0 & 0 & 0 \\
\hline & MSSA and/or MRSA & $7 / 25(28.0)$ & 5 & 1 & 0 & 1 \\
\hline \multirow{4}{*}{$\begin{array}{l}\text { Long-term } \\
\text { care facility }\end{array}$} & MSSA & $8 / 25(32.0)$ & 3 & 1 & 3 & 1 \\
\hline & MRSA & $0 / 25(0.0)$ & 0 & 0 & 0 & 0 \\
\hline & MSSA and MRSA & $1 / 25(4.0)$ & 0 & 1 & 0 & 0 \\
\hline & MSSA and/or MRSA & $9 / 25(36.0)$ & 3 & 2 & 3 & 1 \\
\hline
\end{tabular}

Note. The left and right wheelchair handles were considered as a single site

Table 3 shows S. aureus contamination of door handles separately in the groups disinfected or not disinfected with alcohol once daily in the hospital and affiliated long-term care facility. The $S$. aureus contamination density did not differ between the two groups $(p>.05)$. The MRSA contamination density also did not differ significantly between them $(p>.05)$.

Table 3. Contamination of door handles by MSSA/MRSA in the disinfection and nondisinfection groups in a hospital with a long-term care facility

\begin{tabular}{llll}
\hline Contaminant & Disinfection & $\begin{array}{l}\text { No. of contaminated samples/ } \\
\text { No. of samples examined (\%) }\end{array}$ & cfu/door handle (mean \pm SD) (range) \\
\hline \multirow{2}{*}{ MSSA } & Once daily* $^{*}$ & $39 / 150(26.0)$ & $69.5 \pm 192.1(3-960)$ \\
\multirow{2}{*}{ MRSA } & Nondisinfection $^{* *}$ & $51 / 150(34.0)$ & $87.9 \pm 406.7(3-2,850)$ \\
& Once daily & $20 / 150(13.3)$ & $28.2 \pm 47.8(3-210)$ \\
\multirow{2}{*}{ MSSA and/or MRSA } & Nondisinfection & $27 / 150(18.0)$ & $28.6 \pm 58.2(3-300)$ \\
& Once daily & $49 / 150(32.7)$ & $66.8 \pm 188.6(3-960)$ \\
& Nondisinfection & $64 / 150(42.7)$ & $82.2 \pm 366.6(3-2,850)$ \\
\hline
\end{tabular}

Note. The door handles inside and outside a room were considered as a single site. ${ }^{*}$ Door handles were disinfected with ethanol once daily for 5 consecutive days and examined just before next disinfection; ${ }^{* *}$ Door handles were disinfected once with ethanol, not disinfected for the subsequent 5 consecutive days, and then examined.

\section{DiscuSSION}

In a hospital with a long-term care facility, we selected door and wheelchair handles as representative frequently touched surfaces and investigated their S. aureus contamination rates. S. aureus was frequently detected on door and wheelchair handles $(27.5 \%-51.4 \%)$ in both the hospital and care facility. These results suggest that $S$. aureus, which is an indigenous bacterium in the nasal cavity and a major infectious pathogen, is frequently attached to environmental surfaces not only in hospitals but also in long-term care facilities. In addition, MRSA was detected on door handles in both the hospital and care facility. These results provide supporting evidence that many patients and residents are colonized with MRSA in hospitals and long-term care facilities. ${ }^{[13-18]}$ Of MRSA-

Published by Sciedu Press colonized residents in long-term care facilities, $25 \%$ were reported to develop MRSA infection. ${ }^{[19]}$ The maintenance of environmental cleanliness in these facilities is therefore important.

The Centers for Disease Control and Prevention guidelines state: "Clean and disinfect frequently touched surfaces (e.g., door knobs, surfaces in and surrounding toilets in patients' rooms) on a more frequent schedule compared to that for other surfaces (e.g., horizontal surfaces in waiting rooms)." "[20] The disinfection of frequently touched surfaces as often as possible would be desirable. However, in terms of manpower resources, disinfection more than a few times daily is difficult. Therefore, we evaluated $S$. aureus contamination of door handles in sites disinfected or not disin- 
fected with alcohol once daily. The S. aureus and MRSA contamination rates were lower on door handles disinfected with alcohol once daily, but the $S$. aureus and MRSA contamination densities did not differ significantly between the disinfection and nondisinfection groups. Therefore, disinfection with alcohol once daily is inadequate for maintaining the cleanliness of door handles. This may be because such surfaces are frequently touched by residents or patients with S. aureus or MRSA on their hands. Even after the disinfection of frequently touched surfaces, reinfection may occur soon. Hand hygiene is therefore a basic necessity. However, environmental disinfection can be performed more readily and accurately at a lower cost than hand hygiene. In the future, we intend to evaluate the maintenance of cleanliness after wiping frequently touched surfaces with alcohol two or three times daily.

\section{Conclusion}

Wiping with alcohol once daily at 24-hour intervals was not always effective in maintaining the cleanliness of door and wheelchair handles in a hospital and long-term care facility.

\section{ACKNOWLEDGEMENTS}

The authors thank Dr. Akihiro Sawa of Hiroshima International University, Hiroshima, Japan, for her help and support with statistical analysis.

\section{CONFlicts OF INTEREST Disclosure}

We declare that we have no conflict of interest to report.

\section{REFERENCES}

[1] Rutala WA, Weber DJ. The benefits of surface disinfection. Am J Infect Control. 2004; 32: 226-231. PMid: 15175619. http: //dx.doi.org/10.1016/j.ajic.2004.04.197

[2] Sexton T, Clarke P, O'Neill E, et al. Environmental reservoirs of methicillin-resistant Staphylococcus aureus in isolation rooms: correlation with patient isolates and implications for hospital hygiene. J Hosp Infect. 2006; 62: 187-194. PMid: 16290319. http: //dx.doi.org/10.1016/j.jhin.2005.07.017

[3] Boyce JM, Potter-Bynoe G, Chenevert C, et al. Environmental contamination due to methicillin-resistant Staphylococcus aureus: possible infection control implications. Infect Control Hosp Epidemiol 1997; 18: 622-627. PMid: 9309433. http://dx.doi.org/10.23 07/30141488

[4] Rampling A, Wiseman S, Davis L, et al. Evidence that hospital hygiene is important in the control of methicillin-resistant Staphylococcus aureus. J Hosp Infect. 2001; 49: 109-116. PMid: 11567555. http://dx.doi.org/10.1053/jhin.2001.1013

[5] Dancer SJ. Importance of the environment in meticillin-resistant Staphylococcus aureus acquisition: the case for hospital cleaning. Lancet Infect Dis. 2008; 8: 101-113. PMid: 17974481. http: //dx.doi.org/10.1016/S1473-3099(07) 70241-4

[6] Chang S, Sethi AK, Stiefel U, et al. Occurrence of skin and environmental contamination with methicillin-resistant Staphylococcus aureus before results of polymerase chain reaction at hospital admission become available. Infect Control Hosp Epidemiol. 2010; 31: 607-612. PMid: 20397963. http://dx.doi.org/10.1086/652775

[7] Goodman ER, Platt R, Bass R, et al. Impact of an environmental cleaning intervention on the presence of methicillin-resistant Staphylococcus aureus and vancomycin-resistant enterococci on surfaces in intensive care unit rooms. Infect Control Hosp Epidemiol. 2008; 29: 593-599. PMid: 18624666. http://dx.doi.org/10.1086/5 88566

[8] Stephanie JD. Importance of the environment in meticillin-resistant Staphylococcus aureus acquisition: the case for hospital cleaning. Lancet Infect Dis. 2008; 8: 2101-2113. PMid: 17974481. http://dx.doi.org/10.1016/S1473-3099(07) 70241-4

[9] Carling PC, Parry MF, Bruno-Murtha LA, et al. Improving environmental hygiene in 27 intensive care units to decrease multidrug- resistant bacterial transmission. Crit Care Med. 2010; 38: 1054-1059. PMid: 20081531. http://dx.doi.org/10.1097/CCM. 0b013e3 $181 \mathrm{cdf} 705$

[10] Hakuno H, Oie S, Furukawa H. Contamination of wheelchairs by Staphylococcus aureus. Journal of Hospital Administration. 2013; 2 55-60. http://dx.doi.org/10.5430/jha.v2n2p55

[11] Dettenkofer M, Merkel H, Mutte J, et al. Health Technology Assessment - Do Evidence-based Data for Prevention and Control of MRSA Exist? Klinikarzt. 2004; 33: 15-20. http://dx.doi.org/10.10 $55 / \mathrm{s}-2004-819023$

[12] Jeng DK, Lin LI, Hervey LV. Importance of ultrasonication conditions in recovery of microbial contamination from material surfaces. J Appl Bacteriol. 1990; 68: 479-484. http://dx. doi .org/10.11 11/j.1365-2672.1990.tb02899.x

[13] Bradley SF, Terpenning MS, Ramsey MA, et al. Methicillin-resistant Staphylococcus aureus: colonization and infection in a long-term care facility. Ann Intern Med. 1991; 115: 417-422. PMid: 1908198. http://dx.doi.org/10.7326/0003-4819-115-6-417

[14] Fraise AP, Mitchell K, O'Brien SJ, et al. Methicillin-resistant Staphylococcus aureus (MRSA) in nursing homes in a major UK city: an anonymized point prevalence survey. Epidemiol Infect. 1997; 118: 1-5. PMid: 9042029. http://dx.doi.org/10.1017/S09502688 96007182

[15] Mody L, Kauffman CA, Donabedian S, et al. Epidemiology of Staphylococcus aureus colonization in nursing home residents. Clin Infect Dis. 2008; 46: 1368-1373. PMid: 1841943. http://dx.doi . org $/ 10.1086 / 586751$

[16] Furuno JP, Hebden JN, Standiford HC, et al. Prevalence of methicillin-resistant Staphylococcus aureus and Acinetobacter baumannii in a long-term acute care facility. Am J Infect Control. 2008; 36: 468-471. PMid: 18786448. http://dx.doi.org/10.1016/j .ajic.2008.01.003

[17] Garazi M, Edwards B, Caccavale D, et al. Nursing homes as reservoirs of MRSA: myth or reality? J Am Med Dir Assoc. 2009; 10: 414-418. PMid: 19560719. http://dx.doi.org/10.1016/j.j amda. 2009.02.014

[18] Furuno JP, Shurland SM, Zhan M, et al. Comparison of the methicillin-resistant Staphylococcus aureus acquisition among rehabilitation and nursing home residents. Infect Control Hosp Epidemiol. 
2011; 32: 244-249. PMid: 21460509. http://dx.doi.org/10.10 $86 / 658667$

[19] Muder RR, Brennen C, Wagener MM, et al. Methicillin-resistant staphylococcal colonization and infection in a long-term care facility. Ann Intern Med. 1991; 114(2): 107-112. PMid: 1984384. http://dx.doi.org/10.7326/0003-4819-114-2-1-107
[20] Siegel JD, Rhinehart E, Jackson M, et al. 2007 Centers for Disease Control and Prevention. Guideline for Isolation Precautions: Preventing Transmission of Infectious Agents in Healthcare Settings. Am J Infect Control. 2007 Dec; 35(10 Suppl 2): S65-164. PMid: 18068815. 